\title{
Predictive factors associated with successful bilateral Sentinel Lymph Node mapping in early- stage cervical cancer
}

Bresset A. ${ }^{1,2}$, Balaya V. ${ }^{1,2 *}$, Guani B. ${ }^{3}$, Magaud L. ${ }^{4}$, Montero Macias R. ${ }^{1,2}$, Delomenie M. ${ }^{1,2}$, Bonsang-Kitzis H. ${ }^{1,2}$, Ngô C. ${ }^{1,2}$, Bats AS. ${ }^{1,2}$, Mathevet P. ${ }^{3}$, Lécuru F. ${ }^{1,2}$

\section{Introduction}

\section{- The objective of this study was to determine} clinical, tumor and surgical factors associated with sucessful bilateral sentinel lymph node mapping (SBM) in early-stage cervical cancer

\section{Material and Methods}

ASSISTANCE 0 HÔPITAUX PUBLIQUE DE PARIS

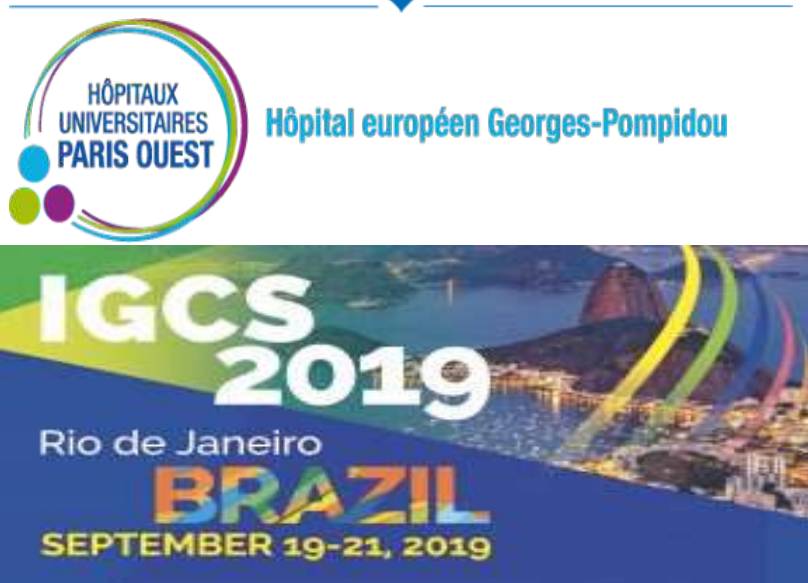

- 405 patients were included for analysis : SLNs were identified on at least one side of the pelvis in 381 patients (94.1\%) and bilaterally in 326 patients $(80.5 \%)$.

The mean age was 45.4 years [22-85 years]. Most patients had IB1 pathologic FIGO 2018 stage $(81.3 \%)$ and squamous cells carcinoma $(71 \%)$.

- Surgeries were mainly performed by mini-invasive approach (368 patients $90.9 \%)$

- By multivariate analysis, lower SBM rate was significantly associated with Age $\geq 70$ years $(\mathrm{ORa}=0.02,95 \% \mathrm{Cl}=[0.002-0.29], \mathrm{p}=0.003)$, tumor size larger than $20 \mathrm{~mm}(\mathrm{ORa}=0.41,95 \% \mathrm{Cl}=[0.19-0.87], \mathrm{p}=0.02)$ and Body-mass index higher than $30 \mathrm{~kg} / \mathrm{m}^{2}(\mathrm{ORa}=0.33,95 \% \mathrm{Cl}=[0.15-0.75], \mathrm{p}=0.01)$. During the inclusion period 2009-2012, SBM was significantly better than during inclusion period 2005-2007 (ORa=2.24, 95\% Cl=[1.09-4.61], $\mathrm{p}<0.03)$.

\begin{tabular}{|c|c|c|c|}
\hline Variable & ORa & IC $95 \%$ & $\mathbf{p}$ \\
\hline \multicolumn{4}{|l|}{ Study inclusion } \\
\hline SENTICOL I (2005-2007) & 1 & & \\
\hline SENTICOL II (2009-2012) & 2.24 & $1.09-4.61$ & 0.03 \\
\hline \multicolumn{4}{|l|}{ Type of inclusion center } \\
\hline Type 1 ( $\leq 5$ patients) & 1 & & \\
\hline Type 2 ( $>5$ patients) & 1.90 & $0.67-5.40$ & 0.23 \\
\hline \multicolumn{4}{|l|}{ Age [years] } \\
\hline$<50$ & 1 & & \\
\hline $50-70$ & 0.18 & $0.02-1.88$ & 0.15 \\
\hline$\geq 70$ & 0.02 & $0.002-0.29$ & 0.003 \\
\hline \multicolumn{4}{|l|}{ BMI $\left(\mathrm{kg} / \mathrm{m}^{2}\right)$} \\
\hline $18.5-25$ & 1 & & \\
\hline$<18.5$ & 1.28 & $0.34-4.87$ & 0.72 \\
\hline$<25-30$ & 0.87 & $0.39-1.95$ & 0.74 \\
\hline$\geq 30$ & 0.33 & $0.15-0.75$ & 0.01 \\
\hline \multicolumn{4}{|l|}{ Parity } \\
\hline 0 & 1 & & \\
\hline$\quad \geq 1$ & 0.65 & $0.30-1.44$ & 0.29 \\
\hline \multicolumn{4}{|l|}{ Menopausal status } \\
\hline No & 1 & & \\
\hline Yes & 2.71 & $0.26-27.83$ & 0.40 \\
\hline \multicolumn{4}{|l|}{ Tumor size } \\
\hline$<20 \mathrm{~mm}$ & 1 & & \\
\hline$\geq 20 \mathrm{~mm}$ & 0.41 & $0.19-0.87$ & 0.02 \\
\hline \multicolumn{4}{|l|}{ FIGO stage (2018) } \\
\hline IA1 with emboli - IA2 & 1 & & \\
\hline IB1 & 0.90 & $0.26-3.07$ & 0.87 \\
\hline IB2 & 0.51 & $0.07-3.55$ & 0.5 \\
\hline IIA-B & 1.76 & $0.30-10.49$ & 0.53 \\
\hline
\end{tabular}

Table 2. Multivariate analysis of predictive factors associated with successful bilateral SLN mapping

\section{Conclusion}

- In early-stage cervical cancer, bilateral SLN detection rates is lower in patients aged more than 70 years, obese patients and larger tumor $\geq 20 \mathrm{~mm}$ whereas stronger experience of SLN biopsy technique improves bilateral SLN detection.

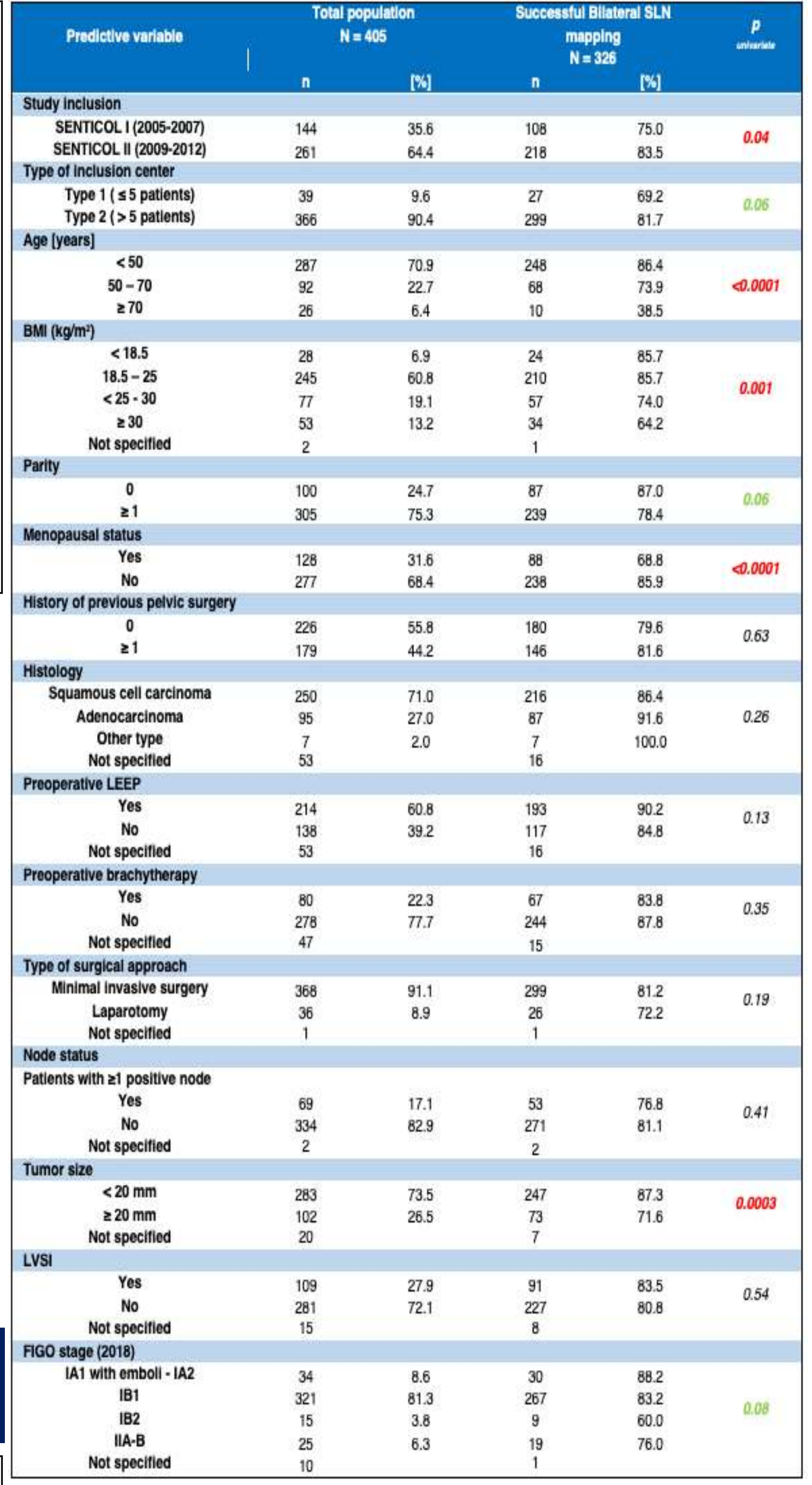

Table 1. Univariate analysis of predictive factors associated with successful bilateral SLN mapping 